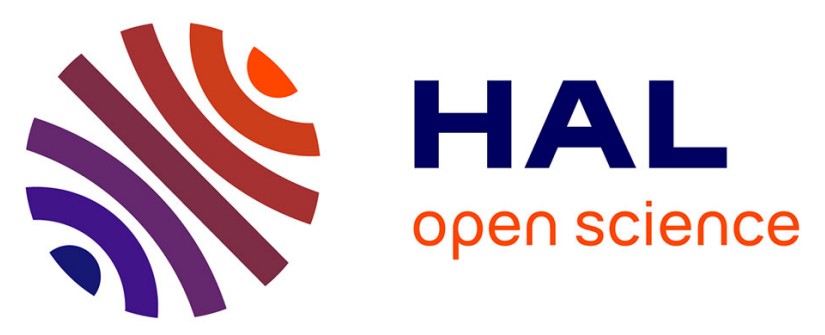

\title{
Clinical Relevance of EGFR - or KRAS - mutated Subclones in Patients With Advanced Non-small-cell Lung Cancer Receiving Erlotinib in a French Prospective Cohort (IFCT ERMETIC2 Cohort - Part 2)
}

Michèle Beau-Faller, Matthieu Texier, Hélène Blons, Nicolas Richard, Fabienne Escande, Samia Melaabi, Sarab Lizard, Florence de Fraipont, Elisabeth Longchampt, Franck Morin, et al.

\section{- To cite this version:}

Michèle Beau-Faller, Matthieu Texier, Hélène Blons, Nicolas Richard, Fabienne Escande, et al.. Clinical Relevance of EGFR - or KRAS - mutated Subclones in Patients With Advanced Non-small-cell Lung Cancer Receiving Erlotinib in a French Prospective Cohort (IFCT ERMETIC2 Cohort - Part 2). Clinical Lung Cancer, 2019, 20 (3), pp.222-230. 10.1016/j.cllc.2018.12.012 . hal-02267702

\section{HAL Id: hal-02267702}

https://hal-normandie-univ.archives-ouvertes.fr/hal-02267702

Submitted on 22 Oct 2021

HAL is a multi-disciplinary open access archive for the deposit and dissemination of scientific research documents, whether they are published or not. The documents may come from teaching and research institutions in France or abroad, or from public or private research centers.
L'archive ouverte pluridisciplinaire HAL, est destinée au dépôt et à la diffusion de documents scientifiques de niveau recherche, publiés ou non, émanant des établissements d'enseignement et de recherche français ou étrangers, des laboratoires publics ou privés.

\section{(ㅇ)(1) $\$$}

Distributed under a Creative Commons Attribution - NonCommerciall 4.0 International 


\section{Clinical Relevance of EGFR- or KRAS- Mutated Subclones}

\section{in Patients with Advanced Non-Small Cell Lung Cancer}

Receiving Erlotinib in a French Prospective Cohort (IFCT

\section{ERMETIC2 Cohort - Part 2)}

Michèle Beau-Faller, MD, PhD, ${ }^{\mathrm{a}, \mathrm{b},{ }^{*}}$ Matthieu Texier, $\mathrm{MSc},{ }^{\mathrm{c}}$ Hélène Blons, PharmD, PhD, ${ }^{b, d}$ Nicolas Richard, PharmD, MSc, ${ }^{e}$ Fabienne Escande, PhD, ${ }^{f}$ Samia Melaabi, MD, ${ }^{g}$ Sarab Lizard, PhD, ${ }^{\mathrm{h}}$ Florence De Fraipont, PharmD, PhD, ${ }^{\mathrm{i}}$ Elisabeth Longchampt, MD, ${ }^{j}$ Franck Morin, MSc, ${ }^{\mathrm{b}}$ Gérard Zalcman, MD, PhD, ${ }^{\mathrm{b}, \mathrm{k}}$ Jean-Pierre Pignon, MD, PhD, ${ }^{c, m}$ Jacques Cadranel, MD, $\mathrm{PhD}^{\mathrm{b}, \mathrm{l}}$

a'Laboratoire de Biologie Moléculaire, Hôpital de Hautepierre, 1 avenue Molière, 67098 Strasbourg, France; Unité INSERM U1113, Streinth Lab, 67200 Strasbourg

France

${ }^{b}$ Intergroupe Francophone de Cancérologie Thoracique (IFCT), 10 rue de la GrangeBatelière, 75009 Paris, France

'Service de Biostatistique et d'Epidémiologie, Gustave-Roussy, 114 rue Edouard Vaillant, 94805 Villejuif, France

${ }^{d}$ Département de Biologie, Hôpital Européen Georges Pompidou, AP-HP, 75015

Paris, France; Université Paris Descartes, 75006 Paris, France

eService de Génétique, Laboratoire de Génétique Moléculaire, CHU de Caen, Caen, France 
'Laboratoire Oncologie et Génétique Moléculaires, Pôle de Biochimie et de Biologie Moléculaire, Centre de Biologie Pathologie, CHRU de Lille, 59037 Lille Cedex,

France

${ }^{9}$ Service de génétique, unité de pharmacogénomique, Institut Curie, Paris, France

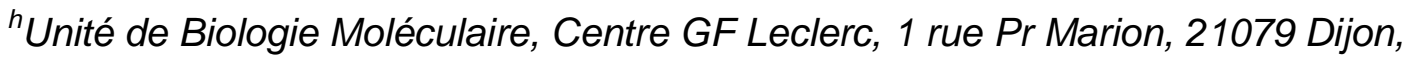
France

'UM Biochimie des Cancers et Biothérapies, CHU Grenoble Alpes; Université

Grenoble Alpes, 38000 Grenoble, France

${ }^{j}$ Service d'Anatomie Pathologique, Hôpital Foch, Suresnes, France

kUMR 830 INSERM et Service d'Oncologie thoracique, Assistance Publique Hôpitaux de Paris, Hôpital Bichat-Claude Bernard, Université Paris-Diderot (Paris 7), 46 rue Henri Huchard, 75018 Paris, France

'Service de Pneumologie, Assistance Publique Hôpitaux de Paris, Hôpital Tenon, GRC-04 Theranoscan, Université Paris VI, 4 rue de la Chine, 75970 Paris Cedex 20,

France

${ }^{m}$ CESP INSERM U1018, Université Paris-Sud, Villejuif, F-94805, France

${ }^{*}$ Corresponding author

Address for correspondence: Michèle Beau-Faller, MD, PhD, Laboratoire de Biologie Moléculaire, Hôpital de Hautepierre, 1 avenue Molière, 67098 Strasbourg, France. Tel.: +33 (0)3 881284 57; Fax: +33 (0)3 881275 39; E-mail:

Michele.FALLER@chru-strasbourg.fr 
Funding: This work was supported by the French League Against Cancer, the French National Cancer Institute (INCa), and Roche Pharma.

\section{Disclosures:}

Pr. Cadranel reports personal fees from Roche, AstraZeneca and BoeringherIngelheim, outside the submitted work.

Pr. Zalcman reports grants and other from Roche, personal fees from BorhingerIngelheim, personal fees and other from Astra-Zeneca, during the conduct of the study; personal fees from BMS, personal fees from MSD, personal fees and other from Pfizer, outside the submitted work.

Other authors have nothing to disclose.

\section{Microabstract (60)}

Detecting driver mutations belongs now to the best practice in advanced/metastatic non-small cell lung cancer (NSCLC). New molecular techniques are highly sensitive. In NSCLC all treated by erlotinib $(\mathrm{n}=228)$, we reports that EGFR and KRAS mutated subclones had a prognostic value, but not minor KRAS mutated sub-clones. Molecular techniques must be sensitive but not under $1 \%$ of mutated tumor cells. 


\section{ABSTRACT (250)}

Introduction: ERMETIC was a prospective study designed to validate the prognostic value of $E G F R / K R A S$ mutations in patients with advanced non-small cell lung cancer (NSCLC), all receiving a first generation TKI, erlotinib. ERMETIC2 was an ancillary project evaluating the clinical value of common EGFR/KRAS-mutated subclones regarding prognosis using highly sensitive molecular detection methods.

Methods: Tumor samples from 228 NSCLC patients (59\% adenocarcinoma, 37\% women, and $19 \%$ never/former smokers) were available for reanalysis using alternative highly sensitive molecular techniques. A multivariate Cox model was used for prognostic analysis.

Results: Using alternative highly sensitive techniques, 16 EGFR and 51 KRAS supplementary mutations were newly identified, all still exclusive, leading to an overall rate of $12.3 \%(n=28)$ and $33.3 \%(n=76)$, respectively. Using real-time polymerase chain reaction (qPCR; hybridization probe), they were significantly associated with progression-free survival (PFS) $(\mathrm{p}=0.02)$ and overall survival (OS) $(\mathrm{p}=0.01)$, which were better for EGFR-mutated patients for PFS (hazard ratio [HR]: 0.46 [95\% confidence interval [CI]: 0.28-0.78]) and OS (hazard ratio [HR]: 0.56 [0.311]), and worse for KRAS mutations and OS (HR: 1.63 [1.09-2.44]). Using the most sensitive technique detection for KRAS - clamp PCR -, KRAS mutated subclones did not impact OS.

Conclusions: KRAS and EGFR mutations were detected in higher proportions by alternative highly sensitive molecular techniques compared to direct Sanger sequencing. However, minor KRAS-mutated subclones offered no prognostic value when representing less than $1 \%$ the tumor cells. 


\section{Keywords}

Driver mutations; Tyrosine kinase inhibitor; NSCLC; molecular techniques; sensitivity 


\section{Introduction}

EGFR tyrosine kinase inhibitors (EGFR-TKIs) erlotinib, gefitinib, and afatinib are authorized worldwide as first-line treatment for advanced or metastatic non-small cell lung cancer (NSCLC) patients with EGFR-activating mutations in their tumor. ${ }^{1,2,3}$ Recently, third generation EGFR-TKI osimertinib has been validated as the standard of care for T790M positive NSCLC in whom disease had progressed during first-line EGFR-TKI therapy. ${ }^{4}$ And more recently, osimertinib showed efficacy superior to that of standard first/second generation EGFR-TKIs in the first-line treatment of EGFR mutation positive advanced NSCLC. ${ }^{5}$

Molecular tumor testing is actually mandatory for selecting first-line treatment in advanced or metastatic non-small cell lung cancer (NSCLC) patients. ${ }^{6-7-8-9}$ Yet no EGFR-mutation assay is currently specifically recommended by the American Food and Drug Administration (FDA), European Agency for the Evaluation of Medicinal Products (EMEA), or European Society of Medical Oncology (ESMO) to inform treatment decisions. ${ }^{10-11}$ Direct sequencing has for many years been considered the gold standard for testing, yet its sensitivity can limit its use to routinely somatic tumor testing, and alternative more sensitive molecular methods - targeted or not - have often since replaced this approach. ${ }^{12}$ Furthermore, next-generation sequencing (NGS) or droplet digital PCR (ddPCR) are developped in molecular platforms. All these highly sensitive molecular methods should be able to detect mutated subclones ( $5 \%$ of mutated cells) to minor subclones $(<1 \%$ of mutated cells), thus raising the question of the prognostic/predictive value of such mutated different subclones. 
Although $K R A S$ is not a target for therapy, lung cancer molecular analyses often test for EGFR as well as KRAS mutations. In Caucasian NSCLC population, EGFR and KRAS mutations are found in $11 \%$ and $29 \%$ of the patients respectively. ${ }^{3}$, ${ }^{7}$ These mutations are often mutually exclusive, hence why some authors have even proposed a step-by-step algorithm using KRAS mutation testing as first step to rule out the presence of an EGFR mutation, in case of using targeted alternative molecular methods. Furthermore, KRAS mutations appear to affect an heterogeneous population with different prognostic/predictive values depending on the type of nucleotide base substitution, regarding EGFR-TKI treatment. ${ }^{13,14}$ Finally, several studies have distinguished patients with EGFR mutations from those with non-EGFR mutated tumors, yet including KRAS-mutated tumors. In our study, we evaluated what impact the mutation detection threshold has on prognostic value of erlotinib efficacy.

The ERMETIC (Evaluation of EGFR Mutation status for the administration of EGFR-TKIIs in non-small cell lung Carcinoma) study, designed and supported by the French Collaborative Thoracic Cancer Intergroup (IFCT), funded by the French $\mathrm{NCl}$ (INCa), reported that formaldehyde-fixed paraffin-embedded (FFPE) specimens may be suitable sources for DNA analysis by means of genomic Sanger sequencing, providing rigorous pre-analytical quality control standards are respected. ${ }^{9,} 12$ Since that publication, ERMETIC centers have switched to alternative molecular methods. The first step of ERMETIC2 consisted in a nationwide technological evaluation of these new EGFR/KRAS testing using NSCLC cell line DNA with various allele proportions. We demonstrated that the best threshold of mutation detection was obtained using allele-specific amplification-based technologies, with cut-off values of $5 \%$ and $1 \%$ for clamped PCR with peptide nucleic acid (PNA). ${ }^{15}$ We report the 
prognosis-based clinical impact of this new strategy on 228 ERMETIC patients with available tumor samples reanalyzed using these techniques.

\section{Patients and Methods}

\section{Patients and Tumor Samples}

The ERMETIC prospective observational study included 522 patients with advanced NSCLC, either newly treated with erlotinib or before erlotinib administration. ${ }^{6} \mathrm{~A}$ preliminary study revealed that EGFR and KRAS mutations identified using Sanger direct sequencing were independent markers of outcome in this population. ${ }^{6} \mathrm{~A}$ subgroup of 228 patients provided sufficient samples for a second round of common EGFR and KRAS mutation screening using the alternative molecular methods selected after ERMETIC2 - part $1 .{ }^{12}$

\section{Biological Assessment}

The methods used were previously described. ${ }^{12}$ Briefly, we used fragment analysis for EGFR exon 19 assessment, and targeted molecular techniques based on allelespecific amplification - probe-specific detection, TaqMan assay - for EGFR exon 21 L858R mutation, and - hybridization probe (SH assay) - without PNA (peptide Nucleic Acid) (KRAS_SH), or with PNA as clamp-PCR strategy (KRAS_PNA) for KRAS mutations.

\section{Statistical Analysis}

Endpoint definitions were as previously defined. ${ }^{6}$ Survival rates were estimated using the Kaplan-Meier method with 95\% Confidence Interval (CI). Impact on survival was quantified using Cox models and hazard ratios with $95 \% \mathrm{Cl}$. Variables with a p-value 
$<0.20$ in univariate analysis were included into the multivariate analysis. A backwards selection process was undertaken with the final model, including all variables with $p$ values $<0.05$.

\section{Results}

\section{Patient Characteristics}

The population consisted of patients with samples available for both EGFR and KRAS mutation analyses, excluding patients with insufficient material for simultaneous analysis of both genes or with non-amplifiable samples. Clinical characteristics of the patients (Table 1) did not differ from those with sample not available for this second $p$ art of the study (data not shown).

\section{EGFR/KRAS Status}

When tumors $(n=228)$ were tested by Sanger direct sequencing, the overall mutation rate was 16.2\% (12 [5.3\%] and 25 [11.0\%] EGFR and KRAS mutations, respectively). When the same tumors $(n=228)$ were tested by molecular alternative methods, the overall mutation rate was 45.6\% (28 [12.2\%] and 76 [33.3\%] EGFR and KRAS mutations, respectively), with 67 new mutations found (16 in EGFR and 51 in KRAS), including $60.8 \%$ (31/51) for KRAS mutations identified using the clamp-PCR strategy (Tables $2 \mathrm{~A}$ and $2 \mathrm{~B}$ ). Details of EGFR and KRAS mutations by techniques are described in Table 3.

\section{Survival Analysis: PFS and OS}

No differences in overall survival (OS) or progression-free survival (PFS) were observed between the initial and re-analyzed ERMETIC populations (data not 
shown). Patients with KRAS-mutated tumors were categorized according to the mutation detection method, SH assay with or without clamp-PCR strategy (KRAS_SH versus KRAS_PNA). The median OS was 15 (95\%Cl: 4.7-28.4), 6.7 (95\%Cl: 2.19.2), $5.3(95 \% \mathrm{Cl}: 3.9-8.1)$, and $2.7(95 \% \mathrm{Cl}: 2.1-9.2)$ months for EGFR-mutated tumors, KRAS_PNA-mutated tumors, EGFR/KRAS wild-type (WT) tumors and for KRAS_SH-mutated tumors, respectively $(\mathrm{p}=0.0018)$ (Fig. 1a). The median PFS was 9.3 (95\%Cl:2.6-15.3), 2.8 (95\% Cl:1.5-3.1), $2.3(95 \% \mathrm{Cl}: 2.0-2.6)$, and $1.6(95 \% \mathrm{Cl}: 0.9-$ 2.5) months for patients with EGFR-mutated, KRAS_PNA-mutated, WT, and KRAS_SH-mutated tumors, respectively $(\mathrm{p}=0.0007)$ (Fig. 1b). The 1-year survival rates $[95 \% \mathrm{Cl}]$ were $60.7 \%$ [42.4; 76.4], 25.8\% [18.9; 34.2], 23.5\% [12.4; 40], and $16.7 \%[8.3 ; 30.6]$ for these four groups, respectively. The clinical characteristics significantly associated with prognosis (OS, PFS) were the same as for the initial population (Table 4 and data not shown). After adjusting for clinical factors, multivariate analysis of mutation status remained significantly associated with OS $(\mathrm{p}=0.01)$ and PFS $(\mathrm{p}=0.02)$ which were better for EGFR-mutated patients for PFS (hazard ratio [HR]: 0.46 [95\% confidence interval [CI]: 0.28-0.78]) and OS (hazard ratio [HR]: 0.56 [0.31-1]), and worse for KRAS mutations for OS (HR: 1.63 [1.092.44]) (Table 4). Using the most sensitive technique detection for KRAS - clamp PCR -, KRAS mutated subclones did not impact OS. EGFR mutation significantly decreased the risk or death by $44 \%$, and the risk of progression or death by $54 \%$ in patients treated with erlotinib. KRAS mutations detected by SH (KRAS_SH) significantly increased the risk of death, by $63 \%$. Conversely, KRAS mutations detected by clamp-PCR strategy (KRAS_PNA) did not increase the risk of death.

\section{Type of KRAS Mutation}


No prognostic value was related to the alteration type (transition/transversion) or mutation location (codon 12 or 13) among the 76 KRAS-mutated patients.

\section{Discussion}

The prognostic or predictive value afforded by driver-mutated subclones and minor sub-clones in NSCLC and other cancer types is still open to debate. With the development of high throughput and extremely sensitive methods, such as NGS, clamp-based PCR, or ddPCR, establishing a cut-off is now mandatory. The clinical value of low allele frequency detection needed to be assessed regarding two issues: Can it rescue mutation testing for small biopsies with low tumor-cell content and high stromal component? Does it have any clinical value?

This study was designed to reanalyze paraffin-embedded NSCLC tumor samples using alternative molecular techniques currently employed in France and many laboratories worldwide thanks to their cost-efficiency for analysis of recurrent genetic alterations, requiring low amounts of DNA from FFPE samples. We described 16 and 51 new EGFR and KRAS mutations, respectively, after reanalysis. In the ERMETIC initial population, EGFR status impacted both PFS and OS, whereas KRAS status only impacted OS. ${ }^{9,12}$ Similar results were observed for EGFR mutation in the re-analyzing study. In contrast, though KRAS status analyzed by PCR using hybridization probes remained predictive of OS, the more-sensitive clamped PCR method that identified low mutated subclones failed to impact prognosis, raising the question of these minor subclones clinical relevance for patient care. 
The number of newly-detected EGFR mutations in our study proved relatively small, suggesting that EGFR mutations are present in the majority of tumor cells or associated with an amplification of the mutated allele in NSCLC, as previously described. ${ }^{16,17}$ We demonstrated that by using sensitive methods we may be able to reattempt detection of an EGFR alteration, an important capability for treatment decisions. All our patients receiving EGFR-TKIs were correctly treated, although the mutation was not identified in the initial ERMETIC study, hence why no modification of EGFR prognostic value was observed between initial and re-analyzing ERMETIC studies. In the latest study, testing was performed using methods with a 10-5\% detection threshold for fragment analysis of EGFR exon 19 deletions and for PCR using TaqMan probes of EGFR L858R mutations. ${ }^{15}$ Therefore, we deduce that the new EGFR-mutated cases were related to the tumor-cell content being low, initially under the level of detecting EGFR mutation by direct sequencing. The unpredictable variability in EGFR copy number and therefore in EGFR wild-type/mutant allelic ratio justifies using sensitive methods to identify patients with EGFR-mutated tumors.

The situation is probably more complex for KRAS mutations in the setting of NSCLC,,${ }^{73}$ with KRAS-mutated subclones previously described in NSCLC. ${ }^{18}$ All the 25 KRAS mutations detected by direct sequencing in the initial population were detected by alternative molecular techniques in the re-analyzing population (internal positive controls). Among the remaining cases, 45 were positive for KRAS mutations (19.7\%) using PCR with hybridization probes and 76 (33.3\%) were detected using more sensitive clamped PCR (no cases with concomitant EGFR mutation). However, this increased sensitivity did not detect any minor subclones as having prognostic impact. Our results suggest that patients with KRAS-mutated subclones, using $1 \%$ as a cut-off (clamp-PCR), behave as with wild-type mutations. Such absence of clinical 
relevance of KRAS-mutated minor subclones was previously described in advanced colorectal cancer (CRC) treated with anti-EGFR therapy. ${ }^{19}$ In NSCLC, it appears that such sensitive methods are not necessarily useful, achieving approximately $1 \%$ detection rate for KRAS mutations.

\section{Conclusion}

Highly sensitive molecular methods increased the number of EGFR and KRAS mutations in NSCLC tumors. For commun EGFR mutations, this increasing is lower and correlated with classical prognostic (OS, PFS) value in first-line EGFR-TKI treated NSCLC patients. For KRAS mutation, detection of mutated subclones (5\%) is associated with survival (OS) but not the minor subclones (<1\%). Our study demonstrated that if more sensitive techniques could detect new mutated cases, it is not necessary to have a too low cut-off for such analysis. Treshold cut-off for mutation analysis must be taking into account for new molecular techniques, as NGS or ddPCR. 


\section{Clinical Practice Points}

- Detecting driver mutations belongs now to the best practice in advanced/metastatic non-small cell lung cancer (NSCLC). New molecular techniques are highly sensitive.

- Highly sensitive molecular methods increased the number of EGFR and KRAS mutations in NSCLC tumors. For common EGFR mutations, this increasing is lower with classical prognostic (OS, PFS) value. For KRAS mutation, detection of mutated subclones is associated with survival (OS) but not the minor subclones.

- Molecular techniques must be sensitive but not under $1 \%$ of mutated tumor cells. 


\section{References}

1. Cadranel J, Ruppert AM, Beau-Faller M, et al. Therapeutic strategy for advanced EGFR mutant non-small-cell lung carcinoma. Crit Rev Oncol Hematol. 2013;88:477-493.

2. Miller VA, Hirsh V, Cadranel J, et al. Afatinib versus placebo for patients with advanced, metastatic non-small-cell lung cancer after failure of erlotinib, gefitinib, or both, and one or two lines of chemotherapy (LUX-Lung 1): a phase $2 b / 3$ randomised trial. Lancet Oncol. 2012;13:528-538.

3. Leduc C, Merlio JP, Besse B, et al.; French Cooperative Thoracic Intergroup (IFCT). Clinical and molecular characteristics of non-small-cell lung cancer (NSCLC) harboring EGFR mutation: results of the nationwide French Cooperative Thoracic Intergroup (IFCT) program. Ann Oncol. 2017 Nov 1;28(11):2715-2724.

4. Mok TS, Wu Y-L, Ahn M-J, et al.; AURA3 Investigators. Osimertinib or PlatinumPemetrexed in EGFR T790M-Positive Lung Cancer. N Engl J Med. 2017 Feb 16;376(7):629-640.

5. Soria JC, Ohe $\mathrm{Y}$, Vansteenkiste $\mathrm{J}$, et al.; FLAURA Investigators. Osimertinib in Untreated EGFR-Mutated Advanced Non-Small-Cell Lung Cancer. N Engl J Med. 2018 Jan 11;378(2):113-125.

6. Beau-Faller M, Prim N, Ruppert AM, et al. EGFR exon 18 and exon 20 mutations in non-small-cell lung cancer on 10117 patients: a multicentre observational study by the French ERMETIC-IFCT network. Ann Oncol. 2014;25:126-131. 
7. Barlesi F, Mazieres J, Merlio JP, et al. Routine molecular profiling of patients with advanced non-small-cell lung cancer: results of a 1-year nationwide programme of the French Cooperative Thoracic Intergroup (IFCT). Lancet. 2016;387:1415-1426.

8. Jackman DM, Miller VA, Cioffredi LA, et al. Impact of epidermal growth factor receptor and KRAS mutations on clinical outcomes in previously untreated non-small cell lung cancer patients: results of an online tumor registry of clinical trials. Clin Cancer Res. 2009;15:5267-5273.

9. Cadranel J, Mauguen A, Faller M, et al. Impact of Systematic EGFR and KRAS Mutation Evaluation on Progression-Free Survival and Overall Survival in Patients with Advanced Non-Small-Cell Lung Cancer Treated by Erlotinib in a French Prospective Cohort (ERMETIC Project-Part 2). J Thorac Oncol. 2012;7:1490-1502.

10. Cree IA, Deans Z, Ligtenberg MJ, et al. Guidance for laboratories performing molecular pathology for cancer patients. J Clin Pathol. 2014;67:923-931.

11. Dietel M, Bubendorf L, Dingemans AM, et al. Diagnostic procedures for nonsmall-cell lung cancer (NSCLC): recommendations of the European Expert Group. Thorax. 2016;71:177-184.

12. Beau-Faller M, Degeorges A, Rolland E, et al. Cross-validation study for epidermal growth factor receptor and KRAS mutation detection in 74 blinded nonsmall cell lung carcinoma samples: a total of 5550 exons sequenced by 15 molecular French laboratories (evaluation of the EGFR mutation status for the administration of EGFR-TKIs in non-small cell lung carcinoma [ERMETIC] project--part 1). $J$ Thorac Oncol. 2011;6:1006-1015.

13. Pan $\mathrm{W}$, Yang $\mathrm{Y}$, Zhu $\mathrm{H}$, et al. KRAS mutation is a weak, but valid predictor for poor prognosis and treatment outcomes in NSCLC: A meta-analysis of 41 studies. Oncotarget. 2016;7:8373-8388. 
14. Yu HA, Sima CS, Shen R, et al. Prognostic impact of KRAS mutation subtypes in 677 patients with metastatic lung adenocarcinomas. J Thorac Oncol. 2015;10:431437.

15. Beau-Faller M, Blons H, Domerg C, et al. A multicenter blinded study evaluating EGFR and KRAS mutation testing methods in the clinical non-small cell lung cancer setting--IFCT/ERMETIC2 Project Part 1: Comparison of testing methods in 20 French molecular genetic National Cancer Institute platforms. J Mol Diagn. 2014;16:45-55.

16. Mansuet-Lupo A, Zouiti F, Alifano M, et al. Intratumoral distribution of EGFR mutations and copy number in metastatic lung cancer, what impact on the initial molecular diagnosis? J Trans/ Med. 2014;12:131.

17. Yatabe $\mathrm{Y}$, Matsuo K, Mitsudomi T. Heterogeneous distribution of EGFR mutations is extremely rare in lung adenocarcinoma. J Clin Oncol. 2011;29:29722977.

18. Marchetti A, Milella M, Felicioni $L$, et al. Clinical implications of KRAS mutations in lung cancer patients treated with tyrosine kinase inhibitors: an important role for mutations in minor clones. Neoplasia. 2009;11:1084-1092.

19. Laurent-Puig P, Pekin D, Normand C, et al. Clinical relevance of KRAS-mutated subclones detected with picodroplet digital PCR in advanced colorectal cancer treated with anti-EGFR therapy. Clin Cancer Res. 2015;21:1087-1097. 


\section{Tables}

Table 1. Patients' Characteristics

\begin{tabular}{|c|c|c|}
\hline & $\begin{array}{c}\text { Frequency } \\
\quad N=228\end{array}$ & $\begin{array}{c}\text { Percentage } \\
\%\end{array}$ \\
\hline \multicolumn{3}{|l|}{ Age (in years) } \\
\hline$<60$ & 84 & 37 \\
\hline $60-69$ & 82 & 36 \\
\hline$>=70$ & 62 & 27 \\
\hline \multicolumn{3}{|l|}{ Sex } \\
\hline Female & 82 & 36 \\
\hline Male & 146 & 64 \\
\hline \multicolumn{3}{|l|}{ Performance status } \\
\hline 0 & 36 & 17 \\
\hline 1 & 98 & 46 \\
\hline 2 or 3 & 77 & 37 \\
\hline Missing & 17 & \\
\hline \multicolumn{3}{|l|}{ Histology } \\
\hline Squamous cell & 48 & 21 \\
\hline Adenocarcinoma & 131 & 57 \\
\hline Others & 49 & 21 \\
\hline \multicolumn{3}{|l|}{ Initial disease stage } \\
\hline I-II-IIIA & 48 & 21 \\
\hline IIIB & 32 & 14 \\
\hline IV & 147 & 65 \\
\hline Missing & 1 & \\
\hline \multicolumn{3}{|c|}{ Initial number of metastatic sites } \\
\hline 0 or 1 & 107 & 47 \\
\hline 2 & 65 & 29 \\
\hline 3 or more & 54 & 24 \\
\hline Missing & 2 & \\
\hline \multicolumn{3}{|c|}{ Localization of metastasis } \\
\hline Brain metastais & 62 & 27 \\
\hline Bone metastasis & 79 & 35 \\
\hline
\end{tabular}




\begin{tabular}{lcc} 
Lung metastasis & 105 & 46 \\
\hline Geographical origin & & \\
Two European parents & 201 & 88 \\
Others & 27 & 12 \\
\hline Smoking status & & \\
Never & 41 & 18 \\
Former & 150 & 66 \\
Current & 35 & 15 \\
Missing & 2 & \\
\hline
\end{tabular}


Tables 2. EGFR and KRAS mutations in the population $(\mathrm{n}=228)$

Table 2A. Categorization of Mutation Status in the population $(n=228)$

\begin{tabular}{lcccc}
\hline $\mathrm{N}=228(\%)$ & $\begin{array}{c}\text { Direct } \\
\text { Sequencing }\end{array}$ & $\begin{array}{c}\text { New mutations } \\
\text { by alternative } \\
\text { molecular } \\
\text { techniques } \\
\text { (including } \\
\text { KRAS_SH) }\end{array}$ & $\begin{array}{c}\text { New KRAS } \\
\text { mutation by } \\
\text { Clamped PCR } \\
\text { (KRAS_PNA) }\end{array}$ & Total \\
\hline EGFR & $12(5.3)$ & $16(7.0)$ & & $28(12.3)$ \\
KRAS & $25(11.0)$ & $20(8.8)$ & $31(13.6)$ & $76(33.3)$ \\
Wild Type & & & & $124(54.4)$ \\
\hline
\end{tabular}

Table 2B. Number of Mutations by Techniques

\begin{tabular}{llll} 
Technique & $\begin{array}{l}\text { EGFR, AT } \\
\text { FA (del19) }\end{array}$ & $\begin{array}{l}\text { EGFR, AT } \\
\text { TaqMan } \\
\text { (L858R) }\end{array}$ & $\begin{array}{l}\text { Total number } \\
\text { of mutations } \\
\mathrm{n}(\%)\end{array}$ \\
\hline $\begin{array}{l}\text { EGFR-SQC } \\
(\mathrm{n}=12)\end{array}$ & 6 & 6 & $12(5.3)$ \\
$\begin{array}{l}\text { New EGFR } \\
\text { mutations } \\
(\mathrm{n}=16)\end{array}$ & 9 & 7 & $16(7)$ \\
$\begin{array}{l}\text { All EGFR } \\
\text { mutations }\end{array}$ & 15 & 13 & $28(12.2)$ \\
\hline $\begin{array}{l}\text { Technique } \\
\text { KRAS, }\end{array}$ & AT_SH & KRAS, & $\begin{array}{l}\text { Total number } \\
\text { of mutations } \\
\mathrm{n}(\%)\end{array}$ \\
\hline $\begin{array}{l}\text { KRAS-SQC } \\
(\mathrm{n}=25)\end{array}$ & 22 & 3 & $25(11)$ \\
$\begin{array}{l}\text { New KRAS } \\
\text { mutations } \\
(\mathrm{n}=51)\end{array}$ & 20 & 31 & $51(22.4)$ \\
$\begin{array}{l}\text { All } \text { KRAS } \\
\text { mutations }\end{array}$ & 42 & 34 & $76(33.3)$ \\
\hline
\end{tabular}

EGFR, SQC: Direct Sequencing; EGFR, ATFA (del 19): Alternative Technique by Fragment Analysis; EGFR, AT TaqMan (L858R): Alternative Technique by probespecific detection with TaqMan assay 
KRAS, SQC: Direct Sequencing; KRAS, AT_SH: Alternative Technique by Hybridization Probe (SH assay); KRAS, AT_PNA: Alternative Technique by clamp$\mathrm{PCR}(\mathrm{SH}+\mathrm{PNA}$ assay) 
Table 3. Detail of EGFR and KRAS mutations detected by molecular methods ( $n=104)$.

EGFR, SQC: Direct Sequencing; EGFR, AT: Alternative Technique (Del19: Fragment Analysis; L858R: probe-specific detection by TaqMan assay)

KRAS, SQC: Direct Sequencing; KRAS, AT_SH: Alternative Technique by Hybridization Probe (SH assay); KRAS,AT_PNA: Alternative Technique by clamp-PCR (SH+PNA assay)

\begin{tabular}{cccccc} 
ID- & $E G F R$, & EGFR, & KRAS, & KRAS, & KRAS, \\
ERMETIC & SQC & TA & SQC & AT_SH & AT_PNA \\
\hline
\end{tabular}

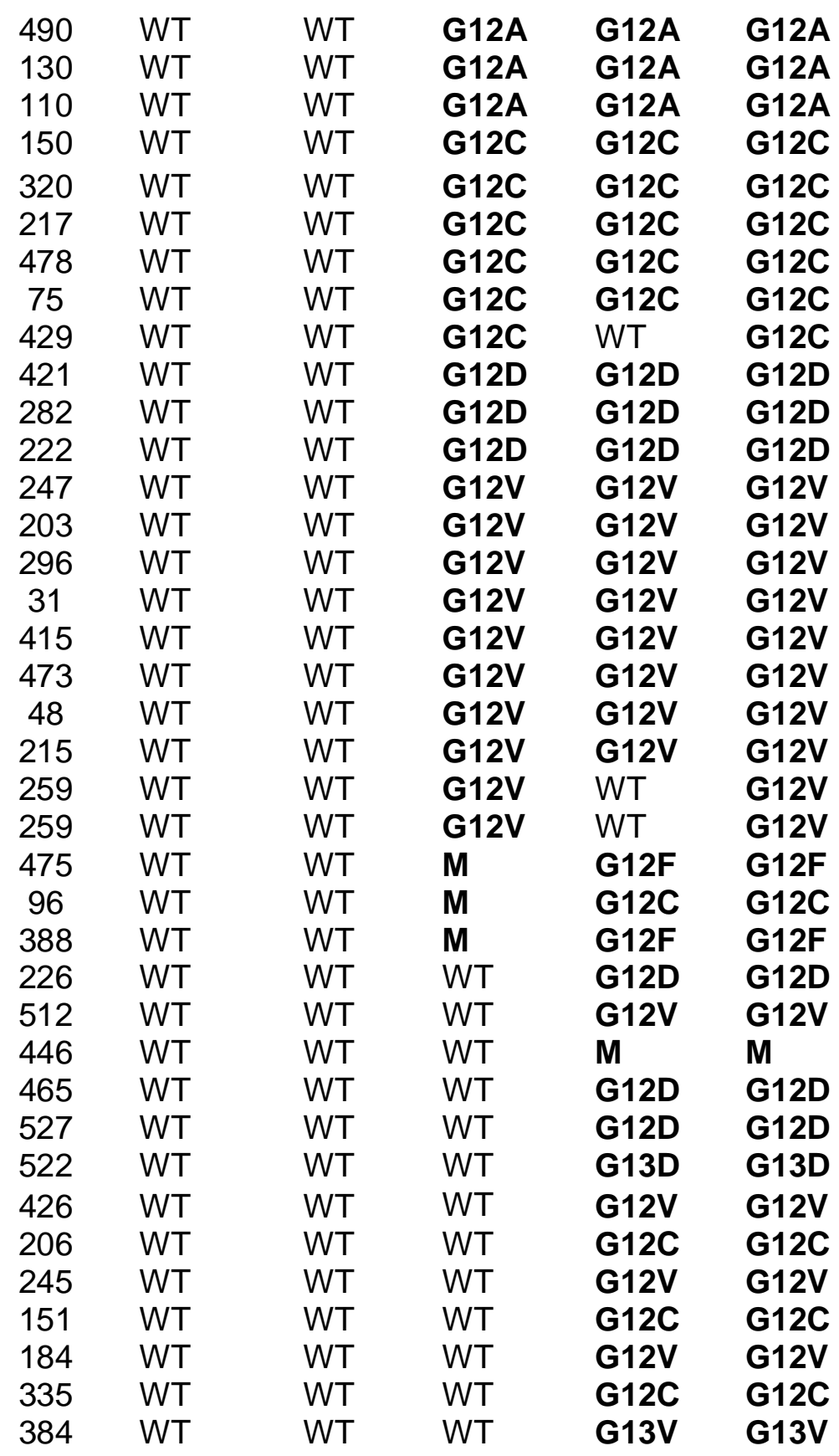




\begin{tabular}{|c|c|c|c|c|c|}
\hline 456 & WT & WT & WT & G12V & G12V \\
\hline 285 & WT & WT & WT & G12A & G12A \\
\hline 80 & WT & WT & WT & G12S & G12S \\
\hline 101 & WT & WT & WT & G12C & G12C \\
\hline 191 & WT & WT & WT & $\mathbf{M}$ & $\mathbf{M}$ \\
\hline 244 & WT & WT & WT & G12C & G12C \\
\hline 286 & WT & WT & WT & G12V & G12V \\
\hline 291 & WT & WT & WT & WT & G12D \\
\hline 303 & WT & WT & WT & WT & G12C \\
\hline 413 & WT & WT & WT & WT & G12S \\
\hline 118 & WT & WT & WT & WT & G12C \\
\hline 205 & WT & WT & WT & WT & G13D \\
\hline 393 & WT & WT & WT & WT & G13D \\
\hline 123 & WT & WT & WT & WT & G12D \\
\hline 391 & WT & WT & WT & WT & G12S \\
\hline 230 & WT & WT & WT & WT & G12D \\
\hline 220 & WT & WT & WT & WT & G12D \\
\hline 234 & WT & WT & WT & WT & G12S \\
\hline 214 & WT & WT & WT & WT & G12D \\
\hline 132 & WT & WT & WT & WT & G12C \\
\hline 453 & WT & WT & WT & WT & G12V \\
\hline 469 & WT & WT & WT & WT & G12R \\
\hline 200 & WT & WT & WT & WT & G12R \\
\hline 254 & WT & WT & WT & WT & G13C \\
\hline 190 & WT & WT & WT & WT & G12C \\
\hline 367 & WT & WT & WT & WT & G12C \\
\hline 34 & WT & WT & WT & WT & G12S \\
\hline 183 & WT & WT & WT & WT & G12S \\
\hline 382 & WT & WT & WT & WT & G12D \\
\hline 401 & WT & WT & WT & WT & G13S \\
\hline 436 & WT & WT & WT & WT & G12C \\
\hline 29 & WT & WT & WT & WT & G12V \\
\hline 443 & WT & WT & WT & WT & G12R \\
\hline 173 & WT & WT & WT & WT & G12V \\
\hline 243 & WT & WT & WT & WT & $\mathbf{M}$ \\
\hline 276 & WT & WT & WT & WT & G12D \\
\hline 368 & WT & WT & WT & WT & G13C \\
\hline 366 & WT & WT & WT & WT & G12F \\
\hline 287 & Del19 & Del19 & WT & WT & WT \\
\hline 375 & Del19 & Del19 & WT & WT & WT \\
\hline 515 & L858R & L858R & WT & WT & WT \\
\hline 233 & Del19 & Del19 & WT & WT & WT \\
\hline 319 & WT & L858R & WT & WT & WT \\
\hline 392 & WT & Del19 & WT & WT & WT \\
\hline 464 & WT & Del19 & WT & WT & WT \\
\hline 545 & WT & Del19 & WT & WT & WT \\
\hline 529 & Del19 & Del19 & WT & WT & WT \\
\hline 269 & WT & Del19 & WT & WT & WT \\
\hline 78 & WT & Del19 & WT & WT & WT \\
\hline 412 & WT & L858R & WT & WT & WT \\
\hline
\end{tabular}




\begin{tabular}{clllll}
135 & Del19 & Del19 & WT & WT & WT \\
364 & WT & Del19 & WT & WT & WT \\
381 & L858R & L858R & WT & WT & WT \\
260 & WT & L858R & WT & WT & WT \\
344 & Del19 & Del19 & WT & WT & WT \\
68 & L858R & L858R & WT & WT & WT \\
534 & L858R & L858R & WT & WT & WT \\
162 & WT & L858R & WT & WT & WT \\
378 & WT & L858R & WT & WT & WT \\
174 & WT & L858R & WT & WT & WT \\
87 & L858R & L858R & WT & WT & WT \\
121 & WT & Del19 & WT & WT & WT \\
196 & WT & L858R & WT & WT & WT \\
242 & WT & Del19 & WT & WT & WT \\
361 & L858R & L858R & WT & WT & WT \\
474 & WT & Del19 & WT & WT & WT \\
\hline
\end{tabular}

WT : Wild-Type

$M$ : Mutation with no precision of the type of mutation 
Table 4. Multivariate Cox model for Survival Analysis $(n=224)$.

\begin{tabular}{|c|c|c|c|c|c|c|}
\hline & & Jverall Survi & & Pro & ession-Free & urvival \\
\hline & HR & $95 \% \mathrm{Cl}$ & p-value & HR & $95 \% \mathrm{Cl}$ & $\mathrm{p}$-value \\
\hline Mutation & & & & & & \\
\hline WT & $1^{*}$ & & 0.01 & $1^{*}$ & & 0.02 \\
\hline EGFR mutation & 0.56 & {$[0.31 ; 1.00]$} & & 0.46 & {$[0.28 ; 0.78]$} & \\
\hline KRAS mutation (PNA) & 1.08 & {$[0.69 ; 1.69]$} & & 1.17 & {$[0.77 ; 1.77]$} & \\
\hline KRAS mutation (SH) & 1.63 & {$[1.09 ; 2.44]$} & & 1.10 & {$[0.74 ; 1.65]$} & \\
\hline Age & & & & & & \\
\hline$<60$ & - & - & - & $1^{*}$ & - & 0.07 \\
\hline $60-69$ & - & - & - & 0.72 & {$[0.50 ; 1.03]$} & \\
\hline$>=70$ & - & - & - & 0.66 & {$[0.45 ; 0.97]$} & \\
\hline Performance status & & & & & & \\
\hline 0 & $1^{*}$ & - & $<10^{-4}$ & $1^{*}$ & - & 0.0006 \\
\hline 1 & 1.52 & {$[0.93 ; 2.47]$} & & 1.86 & {$[1.17 ; 2.94]$} & \\
\hline 2 or 3 & 3.17 & {$[1.90 ; 5.28]$} & & 2.68 & {$[1.66 ; 4.33]$} & \\
\hline Missing & 1.31 & {$[0.62 ; 2.80]$} & & 1.75 & {$[0.86 ; 3.56]$} & \\
\hline Histology & & & & & & \\
\hline Adenocarcinoma & $1^{*}$ & - & 0.06 & $1^{*}$ & - & 0.03 \\
\hline Squamous cell & 1.60 & {$[1.07 ; 2.38]$} & & 1.10 & {$[0.75 ; 1.62]$} & \\
\hline Others & 1.31 & {$[0.90 ; 1.90]$} & & 1.60 & {$[1.12 ; 2.27]$} & \\
\hline Initial number of meta & & & & & & \\
\hline 0 or 1 & $1^{*}$ & - & $<10^{-4}$ & $1^{*}$ & - & 0.0014 \\
\hline 2 & 1.47 & {$[1.02 ; 2.13]$} & & 1.53 & {$[1.07 ; 2.19]$} & \\
\hline 3 or more & 2.50 & {$[1.67 ; 3.74]$} & & 1.93 & {$[1.33 ; 2.80]$} & \\
\hline
\end{tabular}




\begin{tabular}{|lcccccc|} 
No & $1^{*}$ & - & 0.10 & - & - & - \\
Yes & 0.76 & {$[0.54 ; 1.06]$} & & - & - & - \\
Geographical origin & & & & & & \\
Two European parents & $1^{*}$ & - & 009 & - & - & - \\
Others & 0.62 & {$[0.36 ; 1.08]$} & & - & - & - \\
Smoking status(2MD) & & & & & & \\
Never & $1^{*}$ & - & 0.15 & $1^{*}$ & - & 0.07 \\
Former & 1.27 & {$[0.80 ; 2.03]$} & & 1.68 & {$[1.08 ; 2.62]$} & \\
Current & 1.76 & {$[099 ; 313]$} & & 1.73 & {$[0.98 ; 3.05]$} & \\
\hline
\end{tabular}

${ }^{*}$ reference classe

HR: Hazard Ratio; Cl: Confidence Interval

EGFR: fragment analysis (exon 19) and TaqMan assay for L858R; KRAS_SH: real-time polymerase chain reaction (qPCR) with hybridization probe; KRAS_PNA: clamped PCR with peptide nucleic acid (PNA); WT: wild-type EGFR and wild-type KRAS. 


\section{Figure Caption}

Figure 1. Survival curves for patients in the ERMETIC re-analyzing models according to detection technique: 1A) Overall survival; 1B) Progression-free survival. EGFR. EGFR status: fragment analysis for EGFR exon 19 and TaqMan assay for EGFR L858R analysis.

KRAS status: real-time polymerase chain reaction ( $\mathrm{PPCR}$ ) with hybridization probe (KRAS_SH) or clamped PCR with peptide nucleic acid (PNA) (KRAS_PNA). WT: wild-type for EGFR and KRAS mutations. 


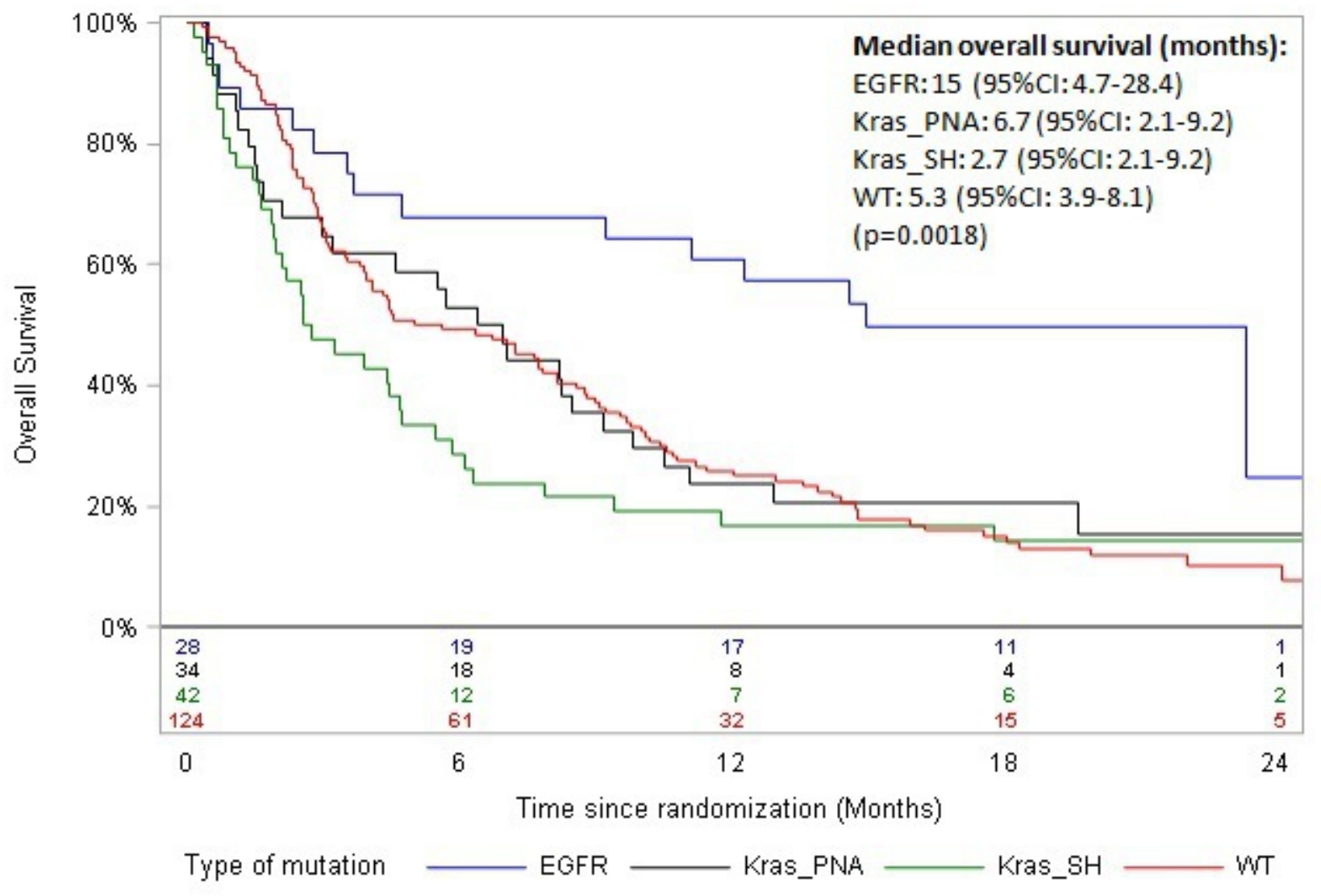




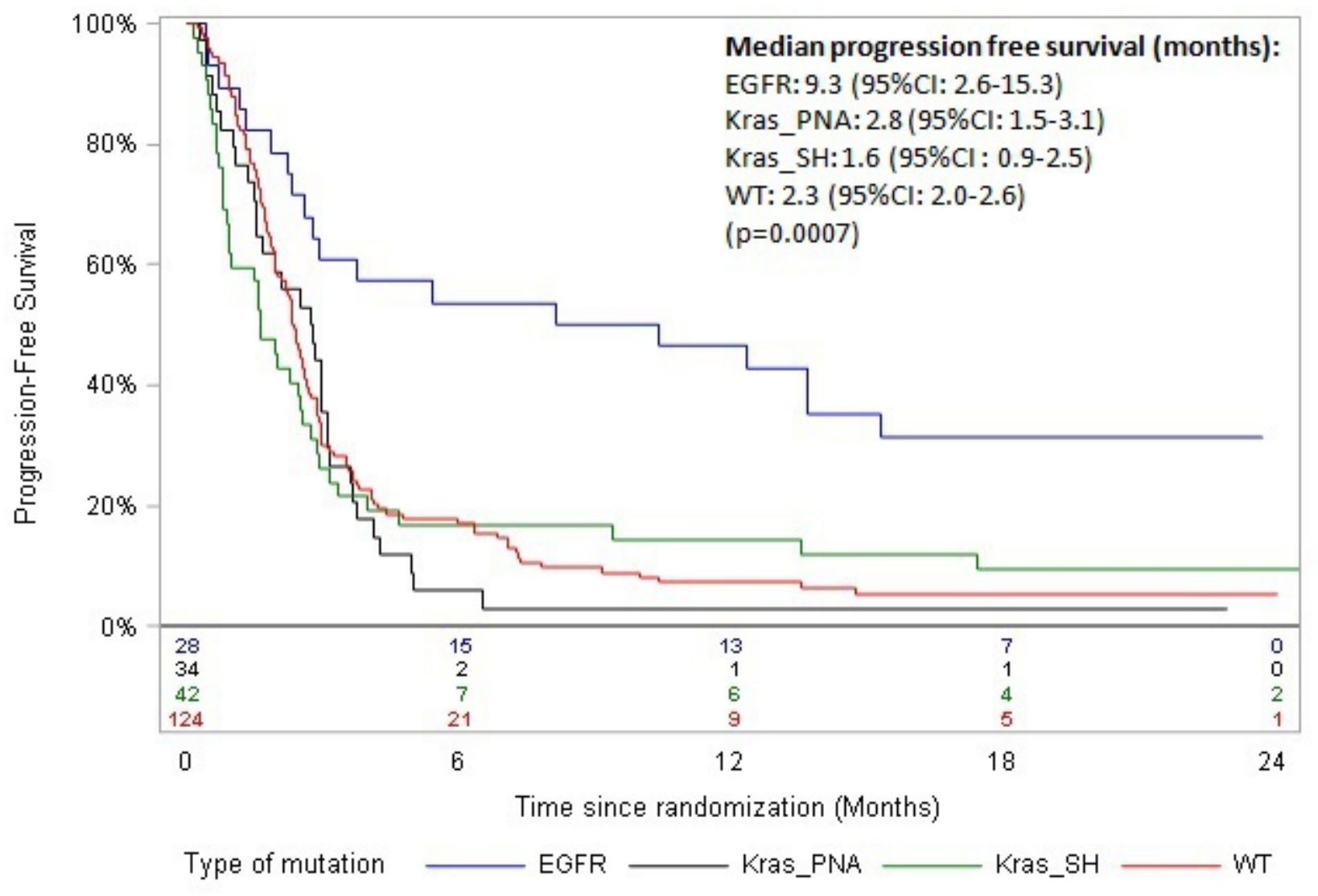

